\title{
The school as a setting for child and adolescent mental health interventions
}

\author{
Many things can wait, \\ The child cannot. \\ Now is the time \\ His blood is being formed, \\ His bones are being made, \\ His mind is being developed. \\ To him, we cannot say tomorrow, \\ His name is today.
}

- Gabriela Mistral

How important are mental disorders in childhood and adolescence? One way of addressing this question is to examine prevalence rates for this age group. In South Africa, we do not yet have valid or reliable prevalence data from samples that are representative of any large populations. This is unfortunate, as such data are useful for service planning and for making the case that mental disorders are important. To fill this gap, an expert task team was convened in the Western Cape to compile estimates of prevalence rates of mental disorders for children, adolescents and adults in that province.' Co-morbidity adjusted annual prevalence rates were derived by consensus. This process was informed by a systematic literature review, and estimates of rates were adjusted to take account of the extent to which risk factors for each disorder were assessed to be present in the province. The overall prevalence rate was assessed to be $17 \%$. The rates for selected disorders were as follows: agoraphobia - 3\%; attention deficit hyperactivity disorder $5 \%$; bipolar disorder - 1\%; conduct disorder - $4 \%$; enuresis $5 \%$; major depressive disorder and dysthymic disorder $-8 \%$; oppositional defiant disorder - 6\%; schizophrenia - $0.5 \%$; separation anxiety disorder $-4 \%$; and simple phobia $-3 \%$. It should be borne in mind that these prevalence rates include only children and adolescents in whom the presence of the disorder was combined with functional disability to the extent that intervention was indicated.

Another way of making a case for the importance of mental disorders in childhood and adolescence involves estimating the proportion of people who develop a disorder in their lifetime who first manifested that disorder when they were young. Until an exciting and methodologically innovative 2005 publication, this information was not available. Kessler et al. ${ }^{2}$ reported data from 9282 individuals in the USA who participated in the National Comorbidity Survey Replication. They reported a lifetime rate of $51 \%$ for any psychiatric disorder. The lifetime prevalence rates for groups of disorders were as follows: anxiety disorders - 32\%; mood disorders - $28 \%$; impulse control disorders loppositional defiant disorder, conduct disorder, attention deficit hyperactivity disorder and intermittent explosive disorder) - 25\%; and substance use disorder - 16\%. What is really striking is the ages of onset of the disorders. For example, $50 \%$ of people who develop any disorder in their lifetime will do by the age of 14 years. The corresponding ages for the groups of disorders mentioned above are as follows: anxiety disorders - 11 years; mood disorders - 30 years; impulse control disorders - 11 years; and substance use disorders -20 years. These findings are of course applicable to the USA, but there is no reason to think that the figures for South Africa would not be similar. The authors of this paper have solid grounds for their conclusion that 'Given the enormous personal and societal burdens of mental disorders, these observations should lead us to direct a greater part of our thinking about public mental health interventions to the child and adolescent years and, with appropriately balanced considerations of potential risks and benefits, to focus on early interventions aimed at preventing the progression of primary disorders.'

Is the mental health care system in South Africa equipped to rise to this challenge? Clearly not. Excellent sub-specialist services are available in certain metropolitan centres. However, there is limited paediatric psychiatric input at primary and secondary levels, and services are largely inaccessible to those living in rural areas. For example, in the Northern Cape (the province with the largest land mass and smallest population) there is just one psychiatrist for people of all age groups, whose mode of transport to his clinics is a small airplane. ${ }^{3}$ No province has a formally established and structured child and adolescent mental health team, despite the fact that the National Policy Guidelines for Child and Adolescent Mental Health call for 'consultation, supervision and training ... to personnel on the other tiers'. ${ }^{4}$

These same national policy guidelines recognise that the health system is not the only setting in which mental health services can be delivered. Indeed, it is obvious that if such services were confined to the health system, resource constraints dictate that only a fraction of the unmet need for services would be met. Other settings include the home, family and community; youth clubs and groups; the street; the workplace (for older adolescents); community-based organisations; residential centres; and schools. The school is a particularly important 
setting for the provision of mental health interventions since it has the potential to reach large numbers of young people in a costeffective manner.

It might be argued that the high drop-out rate among school students in South Africa implies that a substantial proportion of adolescents would be excluded from school-based interventions. Indeed, a Cape Town study found that the dropout rate from Grade 8 to the second or third quarter of Grade 12 was a massive 55\%.5 However, almost all South African children attend school for at least a few years; for example, one study found that $97 \%$ of all children aged 10 - 14 years attend school.' So, while there is certainly a high drop-out rate in South African schools, it is also true that there is a very low rate of failure to attend school altogether. Hence, there is the potential to reach almost all children through school-based interventions.

What mental health interventions can be applied in the school setting? Both the National Policy Guidelines for Child and Adolescent Mental Health ${ }^{4}$ and the National Policy Guidelines for Youth and Adolescent Health specify that each of the five general intervention strategies enumerated by the World Health Organization ${ }^{8}$ can be applied in the school setting. These general strategies, with examples of strategies that give expression to each of the general intervention strategies, are provided below:

\section{- Provide a safe and supportive environment:} foster positive role models; institute school policies that proscribe the use of alcohol, tobacco and other drugs; improve the quality of relationships within the school, for example between teachers and students; provide adequate sport and recreation facilities and opportunities.

- Provide information: provide accurate information about mental health issues with a view to destigmatising mental ill-health, promoting mental health and assisting young people and significant adults in their lives to recognise mental health problems and obtain the necessary assistance.

- Build skills: include in existing life-skills programmes measures that promote mental health and prevent suicide.

- Counselling: increase access to counselling opportunities within the school context; educate teachers about how to respond when students approach them for help.

- Access to health services: improve detection rates of mental disorders; develop seamless referral pathways to the health system if a child or adolescent displays evidence of mental health problems.
The paper by Van der Westhuizen and Krüger in this issue of the Journal, entitled 'Observing a decline in general school functioning associated with depressive disorders in children: A potential role for teachers?', is particularly relevant for the last intervention strategy. ${ }^{9}$ Briefly, they suggest that children can be screened for depression using an 8-item questionnaire, and those who screen positive can be referred for further intervention. While implementation of this suggestion would clearly present significant resource and logistical challenges, it provides one example of how the school setting could be exploited to increase detection rates and enhance access to services

The national Department of Health deserves credit for developing and adopting progressive and realistic policy guidelines for child and adolescent mental health. However, in terms of our Constitution it is the responsibility of the provinces to develop policies, which must be compatible with the national policy guidelines. In developing such policies, the provinces would do well to follow the $\mathrm{WHO}$ recommendations for this process as laid out in the booklet entitled Child and Adolescent Mental Health Policies and Plans. ${ }^{10}$ Sadly, no provinces have adopted a policy for child and adolescent mental health care, and most have not yet taken any meaningful steps in this direction. It is an urgent priority to rectify this deficiency.

\section{Alan J Flisher}

Division of Child and Adolescent Psychiatry and Adolescent Health Research Institute University of Cape Town

Kleinjies S, Flisher AJ, Fick $M$, et al. The prevalence of mental disorders among children, adolescents and adults in the Western Cape, Sou h Africa. South African Psychiatry Review (in press).

2. Kessler RC, Berglund P, Demler $O$, Jin R, Merikangas KR, Walter EE. Lifetime prevalence and age-of-onset distributions of DSM-IV disorders in the National Comorbidity Survey Replication. Arch Gen Psychiatry 2005; 62: 593-602.

3. Dawes A, Lund C, Kafaar Z, Brandt R, Flisher AJ. Norms for South African Child and Adolescent Mental Health Services (CAMHS). Report for the Directorate: Mental Health and Substance Abuse, National Department of Hea th (Tender number DOH 48/2003-2004). Cape Town: Human Sciences Research Council and University of Cape Town, 2004.

4. Department of Health. National Policy Guidelines for Child and Adolescent Mental Health. Pretoria: Department of Hea th, 2003.

5. Flisher AJ, Townsend L, Chikobvu P, Lombard C, King G. Sexual behaviour and high-school dropout in Sou h Africa. Paper presented at he 52nd Annual Meeting of the American Academy of Child and Adolescent Psychiatry and $25 \mathrm{~h}$ Annual Meeting of the Canadian Association of Child and Adolescent Psychiatry, Toronto, Canada, 18 - 23 October 2005.

6. National Institute of Economic Policy Children, Poverty and Disparity Reduction: Towards Fulfilling the Rights of South Africa's Children. Pretoria: Reconstruction and Development Programme, Office of he Deputy President, 1996.

7. Department of Health. National Policy Guidelines for Youth and Adolescent Health. Pretoria: Department of Health, 2001.

8. World Heal h Organization. Programming for Adolescent Health and Development. WHO Tech Rep Ser 1999; No 886

9. Van de Wes huizen D, Krüger C. Observing a decline in general school functioning associated wi h depressive disorders in children: A potential role for teachers? South African Journal of Psychiatry 2005; 11 : 96-98 (this issue).

10. World Heal h Organization. Mental Health Policy and Service Guidance Package: Child and Adolescent Mental Health Policies and Plans. Geneva: World Health Organization, 2005. 